Engineering History and Heritage Volume 165 Issue EH3

Creating the right internal climate for the Crystal Palace

Schoenefeldt

\title{
Creating the right internal climate for the Crystal Palace
}

Henrik Schoenefeldt MPhil (Cantab), PhD (Cantab)

Lecturer of Sustainable Design in Architecture, University of Kent,

Canterbury, Kent, UK

This paper explores Joseph Paxton's experiments with climate control inside glasshouses between 1830 and 1850 and how he exploited this experience to achieve the right internal climate for the 1851 Crystal Palace in Hyde Park. The first part investigates various solutions for ventilation and the management of solar radiation, heat loss and humidity inside glass structures that Paxton had developed before his engagement at Hyde Park. It also shows how these solutions were appropriated for Hyde Park and discusses the various alternative ventilation, shading and cooling arrangements that Paxton investigated for the palace before adopting the final strategy. The final section is a brief analysis of the actual performance of the building and explores the steps taken to improve the ventilation. This postoccupancy history suggests that Paxton's previous experience was insufficient to be entirely successful for the Crystal Palace, but it provided Paxton with new insights that informed his design for the ventilation system deployed in the second Crystal Palace at Sydenham (1852-1854).

\section{Paxton's role as an environmental designer}

Past research into the design of the Crystal Palace (Figure 1), a temporary glass structure erected in Hyde Park, London, to house the '1851 Great Exhibition of the Works of Industry of all Nations' has focused on the role of the engineers and contractors in the development of the iron frame and the methods of prefabrication and assembly (Addis, 2006; Hitchcock, 1958; McKean, 1996; Peters, 2000; Thorne, 1987). This paper, however, argues that the exhibition building was the outcome of a cross-disciplinary effort, in which the skills of glasshouse designers in creating the right internal climate were as critical as those of the structural engineers or architects. The contractors Fox and Henderson depended on the horticulturist and glasshouse designer Joseph Paxton for his specialist knowledge and experience with the detailing of glass envelopes and with managing the environmental conditions inside glass structures. Although the climate inside glasshouses was not designed to meet the requirements of humans or artefacts, Paxton was very confident that his design experience allowed him to create large, well lit spaces and to manage the internal climate. The Magazine of Botany, Gardener's Chronicle, Architect's Journal and the Building Gazette report that Paxton developed numerous solutions for managing the humidity, sunlight and solar gains inside glasshouses. Accounts of how this experience influenced the exhibition building are recorded in various lectures, interviews and papers. These sources provide detailed insight into the specific design issues, working methods and objectives underlying Paxton's experimentation in environmental design at Hyde Park and in horticulture (Schoenefeldt, 2011a: chapters 4-8).
This paper argues that the exhibition building was strongly rooted in glasshouse design, which emerged as a specialist design profession in horticulture, yielding a new design approach and working methods that were distinct from both architecture and civil engineering. This new specialism was concerned with the design of artificial environments for plant cultivation. It specialised in the design and construction of glass envelopes and the control of climates inside fully glazed enclosures. Glasshouse designers also introduced scientific working methods into building design, but unlike their civil engineer contemporaries, they were concerned with the environmental rather than the structural dimension of buildings. The exhibition building represented the earliest attempt to adopt a glasshouse specifically for human occupation and the preservation and display of artefacts, rather than the horticultural purposes for which the building type was originally developed. Although numerous attempts had been made to adopt glasshouses as venues for social and cultural events - for example, in the Pantheon Bazaar Conservatory and in the Winter Garden at Regent's Park, these buildings were still designed as habitats for plants, with no special considerations for thermal comfort.

Previous articles by the author (Schoenefeldt, 2008, 2011b) have shown that environmental considerations had been important in the development of the design and that a postoccupancy evaluation was conducted to assess its actual performance. However, this paper explores to what extent Paxton's experience in glasshouse design provided him with the necessary skills to realise the world's first glass exhibition hall. Previous studies acknowledge the horticultural origins of the 


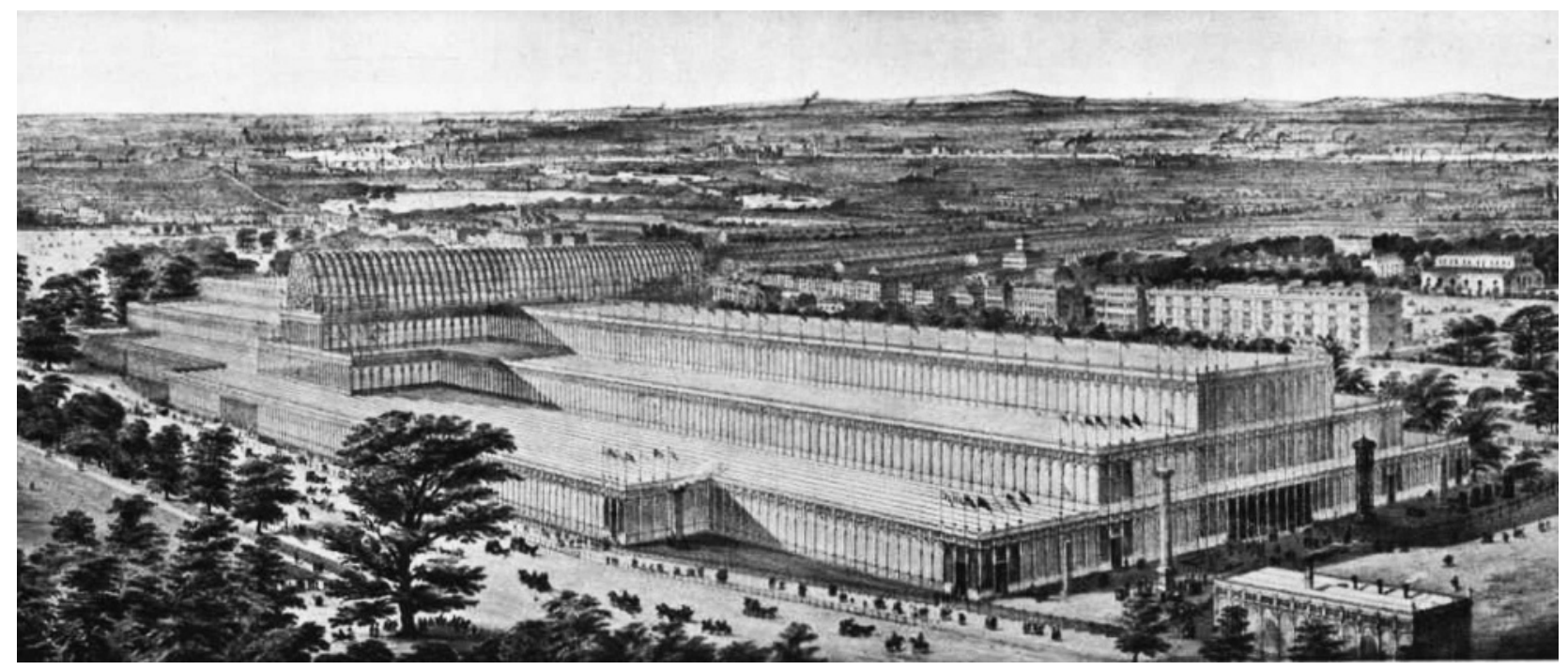

Figure 1. Aerial view of Crystal Palace in Hyde Park, 28 May 1851.

Lithograph by Charles Burton (source: V\&A Museum, London,

museum number 19614)

building (Hix, 1996; Kohlmaier and von Sartory, 1986; Koppelkamm, 1981; Markham, 1935), but these have not shown in any great detail how Paxton's experience as a glasshouse designer enabled him to resolve various environmental design issues. Acting as a precedent for numerous glass exhibition halls in Europe, the exhibition building was decisive in establishing a new, non-horticultural strand within the development of glass structures in the second half of the nineteenth century.

\section{Paxton's efforts to improve the design of glass envelopes}

In July 1851, shortly after Paxton had first published his plans, the press warned of the difficult technical issues that had to be overcome to transform a glasshouse into an exhibition hall. The Times, the Builder and the Building Gazette feared that delicate exhibits, such as carpets, polished iron wares and wall papers, would be damaged if they were exposed to the extreme humidity commonly experienced inside glasshouses, noting that they suffered notoriously from leaks, draughts and condensation. Horticultural journals, however, reveal that the three glazing systems used at Hyde Park (curvilinear and horizontal ridgeand-furrow roofs and the vertical glazing) had been developed by Paxton over 20 years to mitigate the endemic environmental problems of contemporary glazing technology, such as heat loss, condensation and weather tightness problems. Referring to his conservatory at Darley Dale as a precedent, Paxton claimed that it was possible to make glasshouses sufficiently dry for the safe storage of books, fabrics and musical instruments, using his innovative technology. He also wrote that the contractors relied heavily on his technical expertise in the development of the glazing details, which were critical in managing the internal environment. Soon after being appointed head gardener at the Duke of Devonshire's Chatsworth estate in England's Peak District, these environmental concerns drove Paxton to enquire into the development of glazing systems based on timber rather than iron, which had been promoted by his Scottish rival John Loudon since 1817. Paxton argued that while iron-framed glasshouses had been promoted chiefly for their greater transparency to sunlight, other environmental aspects had not received sufficient attention. He stressed that the iron caused severe cold bridging, condensation and suffered weather tightness problems, which he believed it was possible to overcome by developing new timber glazing systems. One objective was to reduce heating costs by minimising heat loss through the building envelope. The adoption of timber, because it was a better insulator than iron, was a first step. Paxton also explored methods of insulating glasshouses during cold nights, using mobile insulating canopies on rails, which could be easily closed or removed at any time.

The details of the ridge-and-furrow glazing was the outcome of a continuous process of refinement, which started with experimental greenhouses in the early 1830s and culminated in the Great Stove, a large tropical conservatory, completed at Chatsworth in 1840. He first developed a timber sash bar, which, due to its tapered form and small cross-section, helped to increase substantially the physical transparency of timberframed glass envelopes. In earlier experiments, he had discovered that the heavy woodwork in existing glasshouses 
Engineering History and Heritage

Volume 165 Issue EH3
Creating the right internal

climate for the Crystal Palace

Schoenefeldt could be lightened without weakening their strength by bevelling off the sides. He achieved sash bars that were as slender as the wrought-iron bars used in the Palm House at Kew. He also cut grooves into the sides of the sash bar to hold the glass and to achieve more durable weather seals. According to Charles Downs the protection of the putty within the groove had made it easier to maintain the weather tightness of glasshouse glazing. In conventional glazing bars, which consisted of a simple shoulder on each side, the putty seals were highly liable to break away under the influence of rain, frost and sunlight, and thereby required regular maintenance.

Furthermore, Paxton used the ridge-and-furrow glazing to replace the conventional method of glazing based on the use of short panes with lap joints. For this purpose he replaced crown glass with patent sheet glass. Crown glass, up until the late 1830 s, was the most commonly used greenhouse glass, but this could only be manufactured in small panes. Sheet glass, which had only been introduced to Britain from France in the early 1930s could be produced in much greater length and enabled Paxton to fill the distance between the ridge-and-furrow beams with a single pane of glass, instead of using multiple overlapping panes, to which he objected, because dirt accumulating in the space between the panes obstructed natural light and gave the glazing an unclean appearance. In his ridge-and-furrow greenhouse of 1834 he had still used panes of only $6 \times 3$ ins $(15 \times 7 \cdot 5 \mathrm{cn})$, but in the Great Stove, where Paxton deployed sheet glass for the first time, the panes were $6 \times 48$ ins $(15 \times 122 \mathrm{~cm})$. To accomplish a spacing of at least $8 \mathrm{ft}(2.4 \mathrm{~m})$ between valley beams, which he aimed to achieve for the sake of greater transparency, Paxton commissioned the manufacturers, the Chance Brothers of Birmingham, to make panes that were $1 \mathrm{ft}(0 \cdot 3 \mathrm{~m})$ longer than those produced commercially. Each pane was fitted into the groove of the sash bar and ridge beam and was sealed with putty on all four sides. The Magazine of Botany and Gardener's Chronicle wrote that Paxton's technology had succeeded in making glasshouses more weather tight than before.

Although the same details were used at Hyde Park, the roof suffered from serious leaks from the start. The first leaks already occurred 2 months before the exhibition opening in May 1851, raising concerns among the Royal Commissioners and exhibitors as to whether the glass envelope would fail to provide adequate protection from the weather. The Times warned that the reputation of the contractor, Paxton and the Commissioners was at stake if these issues were not resolved. Exhibitors feared that rain would damage their goods and in various public letters requested a guarantee that their articles were adequately protected. These early leaks were caused by fractured panes and inadequately sealed joints. Charles Fox wrote that the grooves had not been properly puttied to save time during the construction, but his firm managed to fix this problem temporarily by replacing faulty panes and re-puttying the joints (Seymour et al., 1854). In the first 5 months of the exhibition, leaks were rare and small scale, with leaks occurring mainly in the circular transept roof. Following heavy rainfalls in early October, however, rainwater started entering through the horizontal parts of the roof and in such quantities that it became a nuisance to visitors and a concern to exhibitors. Awnings were installed inside to protect the exhibits. This suggests that Paxton's innovative glazing technology, although it was a great step towards mitigating weather tightness problems in greenhouses, was not sufficient to make glasshouses safe for the display of exhibits.

\section{The management of condensation}

To manage the condensation forming on the underside of the glass, Paxton adopted a system of internal condensation drains, which were first tested inside the Great Stove and the Regia House. Inside the Great Stove he lined both sides of the circular ribs with small gutters (Figure 2(a)) and in the Regia House carved channels into the side of the gutter beams. At Hyde Park, Paxton conceived the glazing as an integral part of his environmental management strategy by which he intended to keep the interior dry, allowing the exhibitors to place their 'manufactures, without the articles, even of polished ware, being tarnished by exposure'. While the ventilation was used to discharge the hot and humid air, the glazing was designed to collect the condensation, caused by the vapour arising from the breath and perspiration of large crowds and from the damp soil under the ground floor boarding. Figure 2(c) shows that condensation drains inside the horizontal roof were cut into the sides of the wooden gutter beams. The condensation collected inside these gutters was drained into a system of cross-gutters, which were connected to the drainpipes inside the cast-iron columns (Figure 3). Inside the barrel vault a similar strategy was deployed, using details originally developed for the Great Stove (Figure 2(b)). The construction drawings show that the internal condensation was collected inside the gutters lining the sides of the wooden arch trusses and discharged onto the flat roof by means of an opening between the ventilators units at the bottom of the vault (Downes and Cowper, 1852). The pitch of the horizontal ridge-and-furrow glazing and the herringbone sash bars of the transept vault were determined by an angle at which the condensation would run down the glass before forming globules large enough to drop from the pane onto the exhibits and people below. In the vertical glazing, channels for receiving condensation and water from leaks were cut into the bottom frame member of each sash. Diagonal drainage holes were drilled into the frame to drain the water onto the external window ledge (Downes and Cowper, 1852). The condensation management reportedly worked very well. The Illustrated London News and Times wrote that condensation formed constantly and in large quantities on the underside of the glass, but was effectively drained away. Charles Fox 
Creating the right internal climate for the Crystal Palace Schoenefeldt

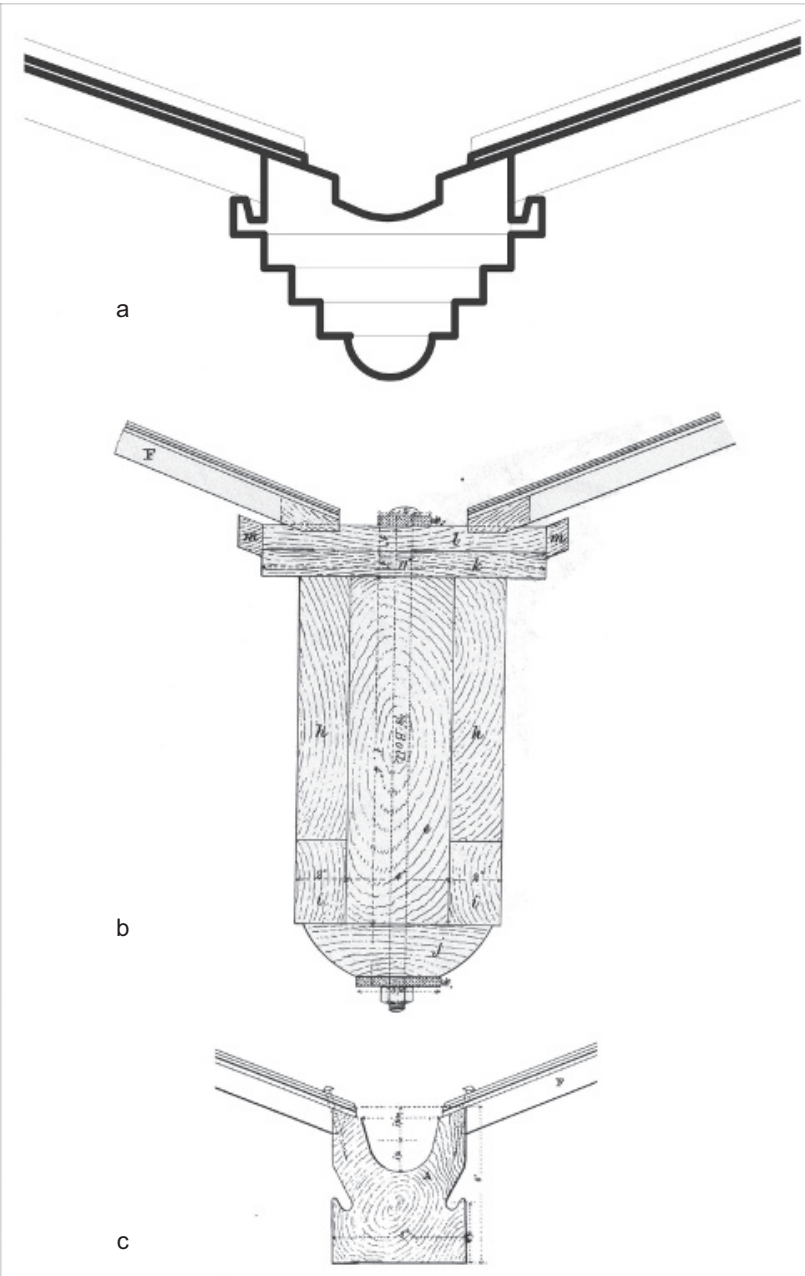

Figure 2. Details of condensation drains used inside the Great Stove (a) and in the flat ridge and furrow roof (c) and barrel vault (b) of the great exhibition building. Figure 1(a) author's own drawing; Figure 1(b) and 1(c) from Downes and Cowper, 1852

wrote that 'any evaporation would never have the power of returning, because the moment it got condensed on the surface of the glass or sash-bars, it could only escape through the gutter'. The executive committee reported that the polished metal wares, which were particularly liable to corrosion, had been successfully preserved up until the last month of the exhibition, when they were tarnished during very foggy weather (Seymour et al., 1854). It is unclear, however, whether the objects were damaged by the condensation or the leaks that started at the same time.

\section{Natural lighting and solar control}

In a lecture given at the Society of Arts in November 1850, Paxton stressed that he used his experience with managing

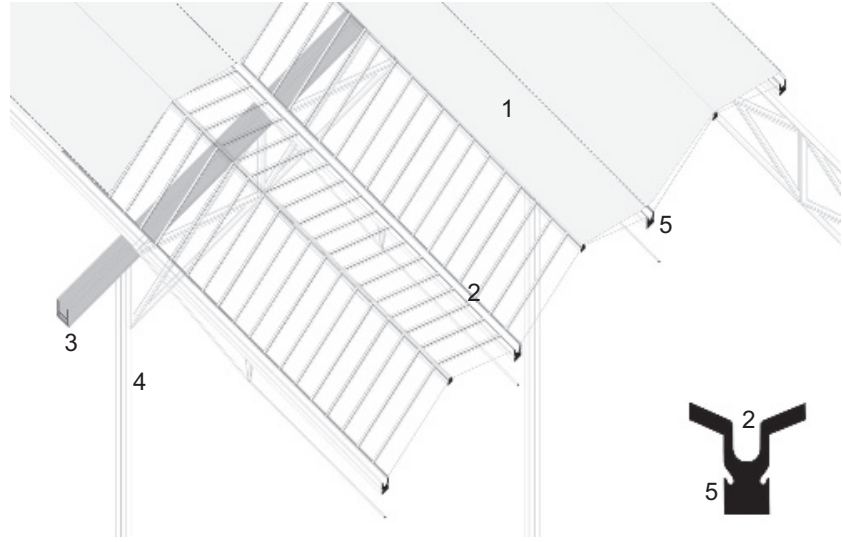

Figure 3. Axonometric projection of the ridge-and-furrow roof at Hyde Park, showing the glazing and shading and drainage arrangements (author's own drawing). (1) Canvas shades; (2) rain gutter; (3) cross-gutter connecting condensation drains and rain gutter with the drainage pipes; (4) drain pipes inside the columns; (5) condensation drains

sunlight inside glasshouses to achieve a completely naturally illuminated exhibition. The horticultural literature records that Paxton had made extensive investigations into the control of sunlight and solar radiation, using the orientation of glazing, different methods of ventilation and shading. The ridge-andfurrow system and vertical glazing were originally developed to optimise the transmission of sunlight at different seasons and during different parts of the day. The Magazine of Botany wrote that his ridge-and-furrow roof was developed to boost the admission of sunlight in the morning and evening. Paxton argued that in conventional lean-to roofs, comprising a single south-facing plane of glass, the morning and evening sunlight is obstructed by the position of heavy rafters and by the oblique angle of the glass surface to the low altitude east and west sun. Instead, Paxton adopted a pleated glass roof, which allowed surfaces to be inclined towards the west and east, so that they were at right angles to the sun in the morning and evening, respectively, when the sunlight is least powerful. By positioning the rafters on two levels, sunlight was also more freely admitted in these periods of the day. During midday, when the sun is most intense, the transmission of light and heat was moderated by ensuring that the glazing was most oblique to the sun. During winter, when the sun is predominantly in the south, the south-facing vertical glazing was used to admit the sunlight instead (Figure 4).

Paxton also recognised that a horizontal ridge-and-furrow roof not only provided a rational means of covering but also lighting spaces of potentially any depth. In his greenhouse of 1834 , which was very deep relative to the morning and evening sun, the east and west facing overhead glazing was used to 
Engineering History and Heritage

Volume 165 Issue EH3
Creating the right internal

climate for the Crystal Palace

Schoenefeldt

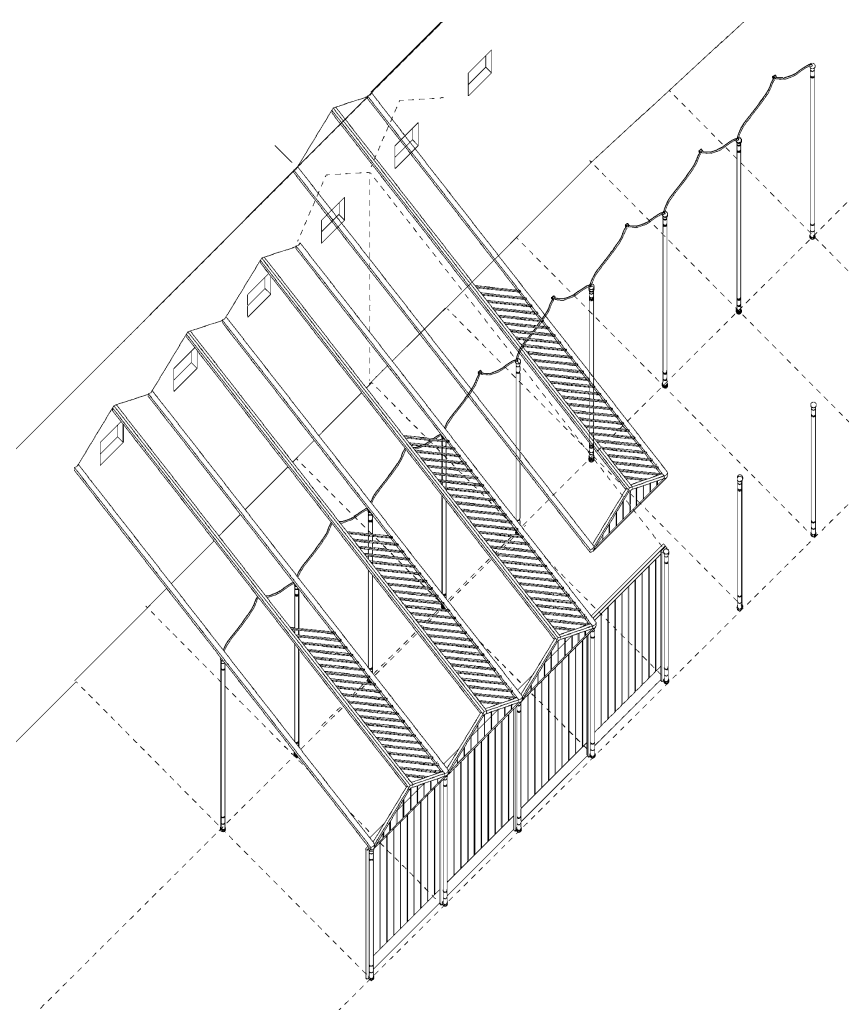

Figure 4. Axonometric projection of Paxton's ridge-and-furrow greenhouse of 1834, showing the removable vertical glazing (based on Paxton (1836))

introduce sunlight throughout the building from the top (Figure 4). These lighting experiments led him to develop a horizontal ridge-and-furrow roof for the Victoria Regia House in 1850, which Paxton described as the model for the toplighting strategy at Hyde Park. To cultivate a specimen of the Victoria Amazonica, a tropical water lily, Paxton required a deep space with the highest possible levels of sunlight. The large lily pond was covered with a continuous glass roof, which admitted sunlight deep into the space. The supporting structure was reduced to a frame of slender cast-iron columns and wrought-iron purlins to achieve the required spans and to minimise the obstruction of sunlight (Figure 5). At Hyde Park, Paxton exploited the same principle to resolve the problem of both the lighting and spanning of large spaces on a much larger scale (Figure 6). To achieve this, however, Paxton relied on the technical skills of the engineers William Barlow, Charles Wild, John Henderson and Charles Fox to develop the freestanding iron-framed structure (Addis, 2006; McKean, 1996; Mallet, 1862).

Paxton, however, admitted that he had to exclude glare to protect exhibits and occupants from the radiant heat of the direct sunlight to make the lighting inside a glasshouse suitable

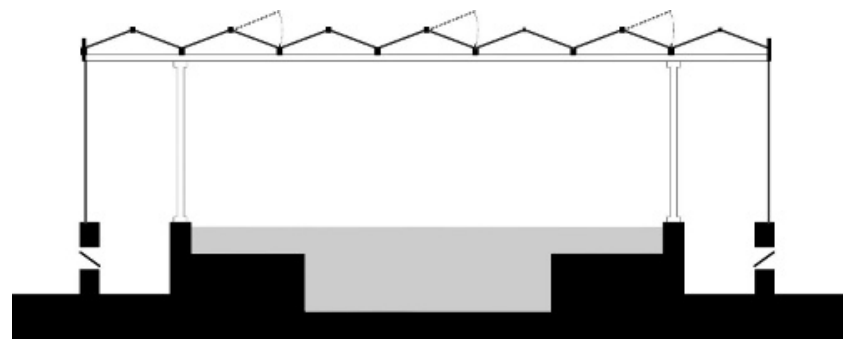

Figure 5. Cross-section of the Victoria Regia House, Chatsworth, showing the dampers inside the plinth, the operable lights hinged to the ridge beams of the roof (author's own drawing)

for the exhibition. For this purpose he covered the entire horizontal roof with translucent calico screens, which cast the interior in a uniform and diffused light. The Journal of Art wrote that 'there is hardly any choice in respect of light, which is nearly equal, and the same in all parts of the building', and the Building Gazette noted that the building would 'show articles as well as if in the open air, but with the advantage of being protected from the direct rays of the sun'. It is to be noted here that Paxton at Hyde Park no longer followed the original solar control principles behind the ridge-and-furrow glazing. The construction drawings show that the roof glazing faced north and south rather than east and west, meaning that large parts of the glass were exposed to the sun at midday. The orientation of the glazing appears to have been determined by site constraints and economic considerations. The shading was used as an alternative solar control strategy. To shield the highly exposed glass roof from direct solar radiation, the calico screens were hung externally rather than internally. Paxton also believed that the solar gains accumulating between the glass and the canvas screens would be removed by the wind. In the original proposal additional shading was to be provided on the exterior of the south elevation, to protect the interior from the sun at midday, but in the final design these shades were installed on the inside instead.

As the top-lighting regime limited the extent to which multiple storeys could be inserted inside an extremely deep building, the first floor gallery was reduced to a network of shallow bridges, which allowed top light to get to the spaces below (Figures 6 and 7). Paxton originally proposed another gallery on the third tier to increase the exhibition space without substantially interfering with the lighting. The building was composed of three tiers of diminished width, forming the shape of a stepped pyramid in cross-section. Paxton had explored the principles of galleries and tiered elevations in various conservatories. In the Great Stove, he used galleries to provide access to the canopies of palm trees without casting too much shade. In the same building he used tiered elevations, composed of curved ridgeand-furrow glazing. In his conservatory at Capethorn Hall, 


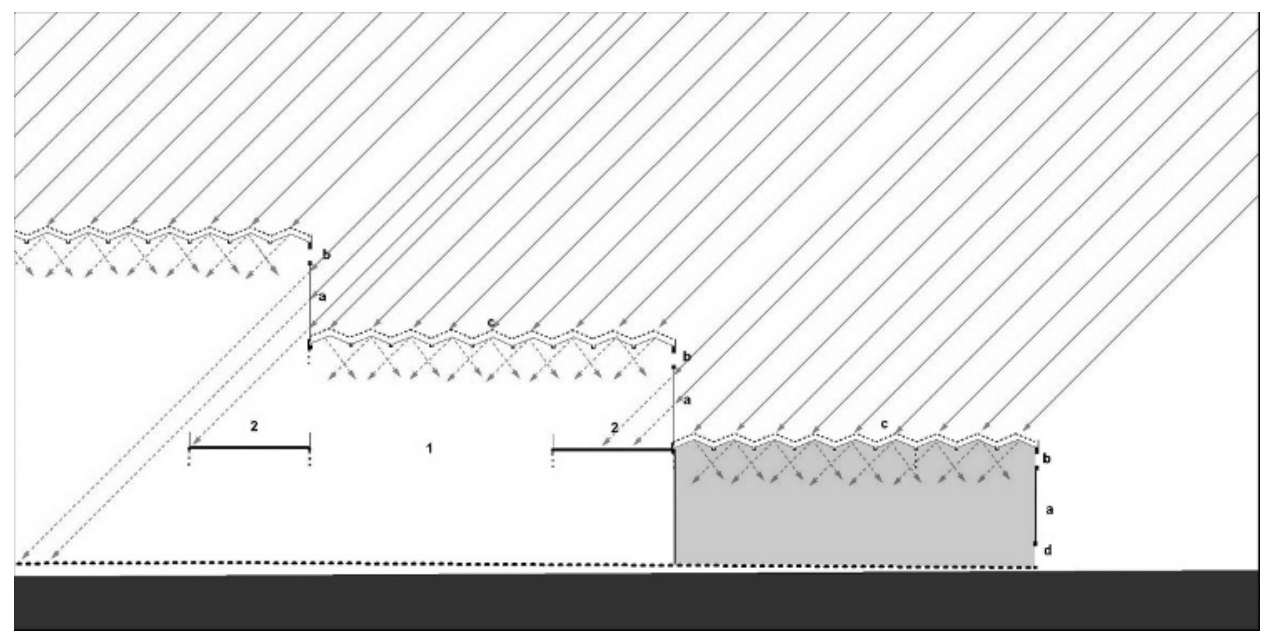

Figure 6. Half cross-section of the Hyde Park building, showing the ventilation and shading arrangements (author's own drawing).

(a) Infill glazing units; (b/d) ventilators; (c) calico shades, covering the ridge-and-furrow glazing; grey: machinery department that was partitioned off from the main space of the building (author's own drawing) conversely he used angular tiers, composed of vertical sashes with a minutely inclined ridge-and-furrow roof, which resembled closely the arrangement at Hyde Park. The Magazine of Botany reported that tiered elevations were originally developed to accommodate plants of different dimensions within a single space, as it was considered important to keep plants as close as possible to the glazing (sunlight was thought to diminish with distance from the glass). At Hyde Park, the tiered elevations permitted the galleries to be kept close to the vertical glazing, which gave access to side lighting. It also facilitated the accommodation of spaces of varying height, such as the three-storey nave and the two-storey exhibition courts in the side aisles. This shows very clearly that conservatories provided a prototype for the natural lighting strategy at Hyde Park, which also bears a striking resemblance to the standard arrangements used in various art and science museums in the second half of the nineteenth century (Physick, 1982; Yanni, 1999).

\section{Enquiries into the ventilation and cooling of glass structures}

Referring to his previous experience in ventilating glasshouses, Paxton claimed that the atmosphere inside the exhibition building could be kept cool and fresh by means of natural ventilation. However, this underestimated the full extent of the challenge, as the exhibition was to be held over the hottest summer months and crowds of tens of thousands were expected (in fact even this proved to be an underestimation as up to 100000 visitors attended on the busiest days of the exhibition). Paxton suggested that the Regia House was a

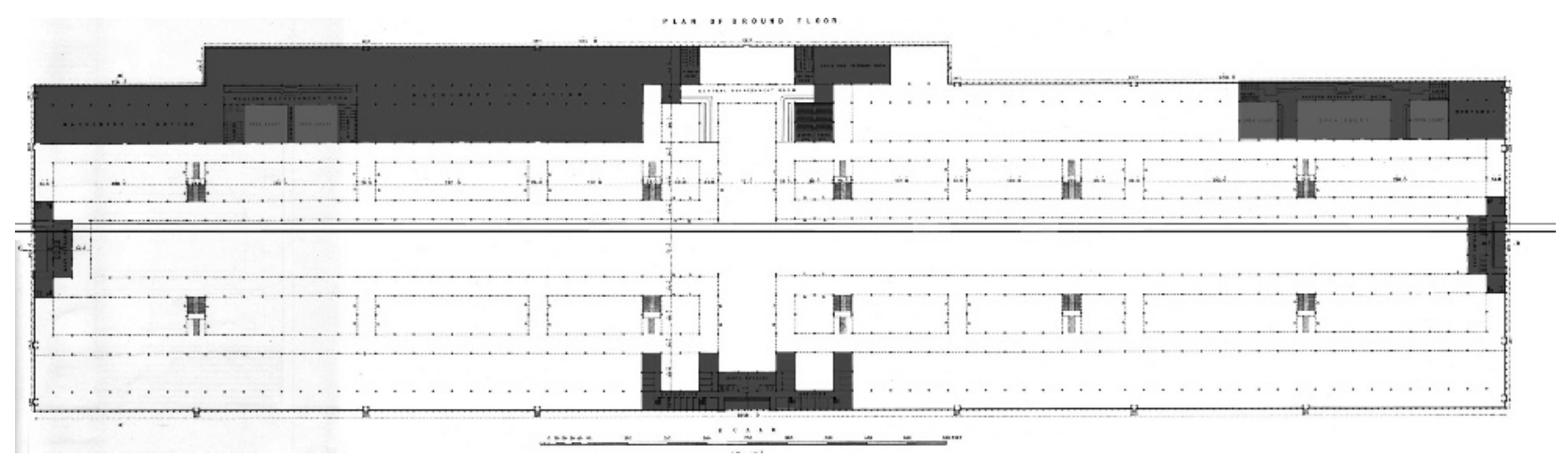

Figure 7. Ground floor plan of the exhibition building, showing the galleries and the spaces partitioned off from the rest of the building (Downes and Cowper, 1852: plate 1, fills added by author) 
Engineering History and Heritage

Volume 165 Issue EH3
Creating the right internal

climate for the Crystal Palace

Schoenefeldt prototypical precedent for the exhibition building, despite his admission that the ventilation system had been designed for the opposite objective, which was to minimise the loss of heat and humidity, as the tropical plants had to be kept constantly inside a hot and humid atmosphere. For this reason the glazing was permanently sealed and ventilation was only provided through small dampers inside the plinth and a series of operable lights inside the roof (Figure 5).

Paxton's only experience with preventing the overheating of glasshouses in summer was the employment of sliding sashes that allowed the entire envelope to be opened to the atmosphere. In his greenhouse of 1834, for instance, he deployed a system of cast-iron columns and mobile vertical sashes (Figure 4). In the conservatory wall at Chatsworth he deployed a system of sliding sashes with brass rollers running in metal tracks, which could be easily opened to admit fresh air. To capture the solar heat during the winter, however, the glazing was closed and small ventilators were used to provide controlled ventilation. At Hyde Park, however, this passive cooling strategy was not feasible, as Paxton also aimed to avoid uncomfortable draughts and to protect the exhibits from the weather. The challenge at Hyde Park was to keep a fully enclosed glasshouse, equipped with much smaller ventilation openings, sufficiently cool; a problem he had not encountered before.

Paxton's original proposal was to fill every third vertical glazing compartment of the upper two tiers with 'lufferboarding' (frames filled with wooden louvres that were sloped to shed off rain) and to introduce bands of low-level ventilators at ground floor level. As cooling had only been a minor concern in glasshouse design, Paxton had to expand enquiries to include non-horticultural precedents that dealt with the question of thermal comfort for humans, such as evaporative cooling methods used in India for the cooling of houses. During periods of extreme heat, he proposed to cool the supply air by moisturising sheets of 'coarse open canvas' covering the ventilators. Paxton claimed to have done a small-scale experiment, in which he used wet canvas to cool the air temperature of a room from $29^{\circ} \mathrm{C}$ to $25^{\circ} \mathrm{C}$ in $1 \mathrm{~h}$. He believed that it was possible to lower the temperature inside the exhibition building below the external temperature. The proposal was criticised in the Builder for damaging vulnerable goods by increasing the interior levels of atmospheric humidity, a possible reason why it was never implemented. $\mathrm{He}$ also believed that he could provide additional cooling by sprinkling water onto the canvas roof covering. Paxton, Fox and Henderson, and the executive committee, however, made further enquiries into the issue of ventilation, leading to significant modifications of the original plans. In the final design they used fixed glazing with narrow bands of adjustable ventilators, which permitted the ventilation to be carefully controlled. Continuous rows of ventilators were built into the top section of each of the three tiers (Figures 6 and 8). Additional rows were introduced at the bottom of the ground floor tier and below the transept vault (Figure 1). The ventilation was regulated by means of horizontal metal louvres, which could be manually opened or closed with the aid of a wheel and cord mechanism designed by Fox and Henderson. This mechanism allowed the Royal Sappers and Miners, who were responsible for managing the ventilation, to operate 24 ventilator units from one position. The S-shaped louvre blades, developed especially for Hyde Park, prevented rain entering the building when the ventilators were open. This permitted continuous ventilation, which was critical in a building for

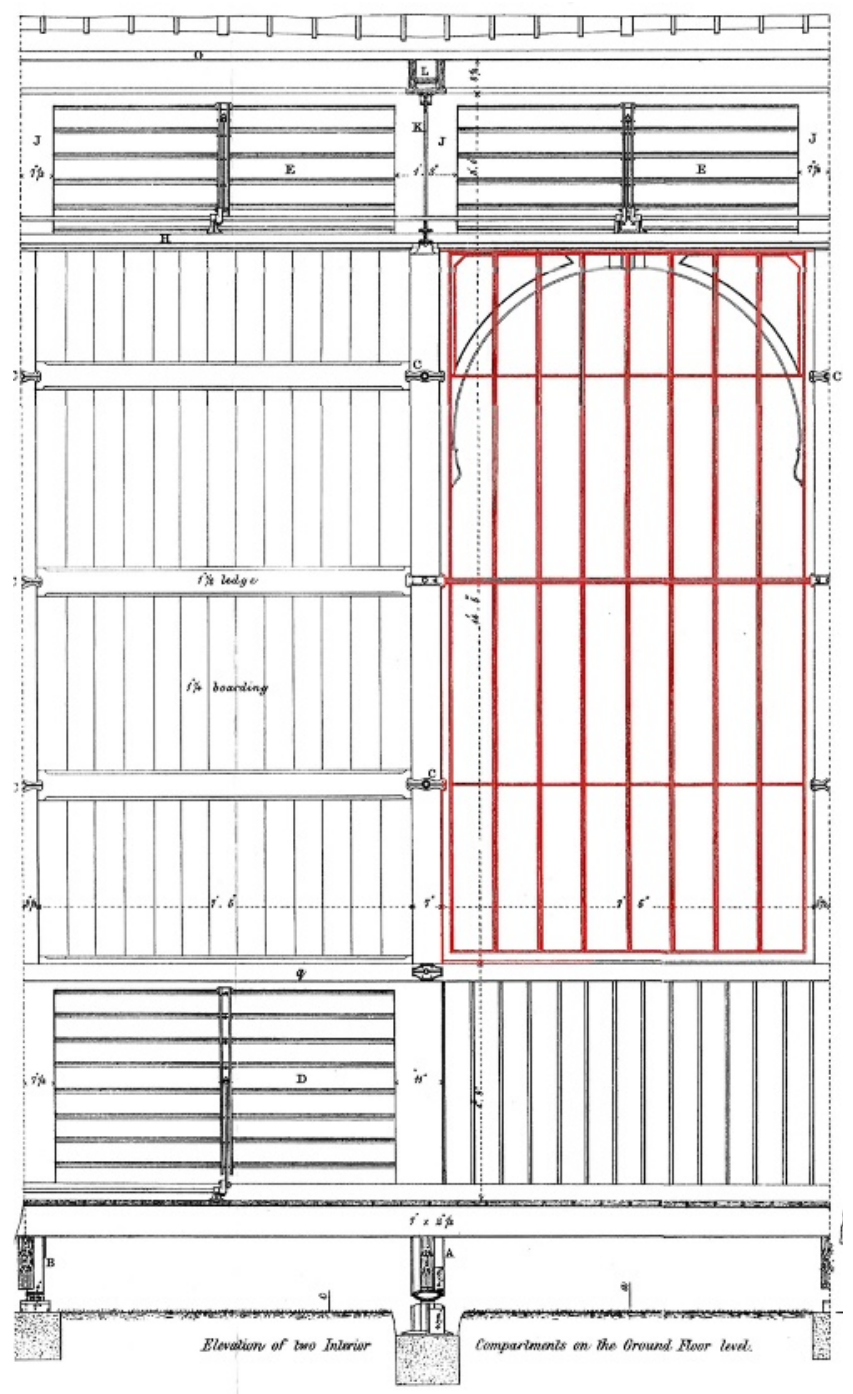

Figure 8. Detail of the vertical façade, showing removable sashes and the louvre ventilators from inside the building (Downes and Cowper, 1852: plate 21) 
mass congregation. Paxton and Cubitt also reported on plans to open the semicircular ends of the transept vault for additional ventilation, helping to expel the hot air. To exclude the rain, the open framework was to be filled with coarse canvas. In the final design, however, it was glazed in and the lost ventilation area was recovered by enlarging the ventilators in other parts of the building. Paxton was confident that the ventilation would be 'ample', 'copious' and he said that 'if he had erred at all in respect of the means of ventilation, there would be found too much rather than too little'. However, the post-occupancy evaluation, which is discussed in the next section, showed that the ventilation was insufficient to prevent serious overheating problems and, despite fears that rain might injure the exhibits, parts of the sashes were removed to boost the ventilation.

The construction details (Downes and Cowper, 1852) indicate that great efforts had been made to make the vertical envelope weather tight for the protection of the exhibits. The vertical glazing was composed of three prefabricated glass sashes and two intermediate timber posts, used to close the space between the structural cast-iron columns of each bay (Figure 8). To achieve a tight fit between the sashes and the circular face of the columns, a circular section was cut into the sides of the sashes. The sashes were pushed tightly against the columns by metal brackets. Strips of wood were used to 'seal' the joint between the bottom of the sash and the sill, and between the top of the sash and the ventilator frames. Each sash was based on similar details to those of the conservatory wall. The vertical panes of glass were fitted into the grooves of the timber sash bars and frames and were sealed with putty. The horizontal joints between individual panes were sealed with a tin came. Despite concerns about the safety of the exhibits, the construction permitted large parts of the vertical envelope to be opened for auxiliary ventilation. Each sash was held in place by six brackets, permitting easy installation and removal.

Aside from modifying the ventilation, Paxton and the contractors considered other ways of passively cooling the interior. Fox suggested an alternative cooling system, comprising a large-scale punkha fan, a traditional Indian fan made of cloth hung from the ceiling and operated by servants. The proposal was to install large sheets of canvas under the roof that were to be kept in a perpetual movement to agitate the interior air. The artificial breeze was to improve thermal comfort. Evaporative cooling was to be provided during extremely hot summer days by moisturising these fans. In the final design no active method of cooling the interior was deployed. The ventilation could do no more than to provide a breeze, equalise the indoor and outdoor temperatures, but the shading protected people from the intense sunlight experienced in the open air.

\section{The scientific assessment of the ventilation system}

Newspaper reports reveal that the executive committee, the Royal Sappers and a thermometer maker collaborated in conducting a post-occupancy evaluation of the ventilation system. The Royal Sappers, responsible for regulating the ventilation, kept $\log$ sheets of the internal temperature. Thermometers were installed within the interior and exterior, and temperatures were recorded at 2-hourly intervals during opening hours from 19 May to 11 October 1851. The data were published in various newspapers and in the First Report of the Royal Commissioners in 1852 (Commissioners for the Great Exhibition, 1852). Newspapers also provide eyewitness accounts of the interior conditions and their effect on people and artefacts and recorded the executive committee's numerous attempts to improve the ventilation during the exhibition. These procedures were not unusual in glasshouse horticulture, in which it was common practice to monitor the internal environment, using empirical observations and measurements, and to optimise the performance of buildings through design modifications. The empirical design approach of glasshouse design was clearly continued at Hyde Park (Schoenefeldt, 2008, 2011).

\section{Experiments with optimising the ventilation as a summer cooling strategy}

Overheating problems were not reported until 27 June 1851, when the temperature had reached $36^{\circ} \mathrm{C}$ for the first time. High temperatures continued until $1 \mathrm{July}$. The heat was not only perceived as uncomfortable, but on 28 June a member of the executive committee also suffered heat stroke and had to be taken outside to recover. The executive committee subsequently held an emergency meeting to develop plans for improving the ventilation. One plan was to admit more fresh air by removing part of the vertical glazing at both ends of the nave and to introduce large operable sashes into the transept roof to expel the hot air. The second plan was to construct a tunnel with a powerful fan to convey cool air from the Serpentine into the building. The Times reported that sashes had been removed in the east and west elevations by 1 July to reduce the temperature and 'to secure a refreshing thorough [sic] draught from end to end of the interior'. While these measures reportedly lowered the temperature at ground level, hot and stuffy air continued to prevail inside the galleries. To overcome this, parts of the glazing in the north and south galleries were removed on 7 July. The glazing was reinstalled by $19 \mathrm{July}$, when the indoor temperature had fallen to $15^{\circ} \mathrm{C}$ and the ventilators were used to regulate the temperature. In late July the building overheated once again, but this time the management removed the glazing in both ends of the transept. In August a more permanent arrangement for auxiliary ventilation was adopted. Ninety vertical sashes, $15 \%$ of all glazing units, were removed in different parts of the building 
and the openings were covered with canvas blinds, which could be opened and closed as required. This shows that the management, in order to manage the combined heat of large crowds and intense solar radiation, opened large parts of the vertical envelope, as Paxton had done in his conservatory wall and early greenhouses. However, recorded data show that even the increased ventilation was not sufficient to prevent the interior from becoming hotter than outdoors (Figure 9). The peak indoor temperatures were consistently between $1{ }^{\circ} \mathrm{C}$ and $8^{\circ} \mathrm{C}$ higher than the peak outdoor temperatures. There were two periods of extreme heat (the first between 25 June and 2 July and the second between 1 August and 22 August), when the peak indoor temperatures constantly exceeded $26^{\circ} \mathrm{C}$. These two periods were separated by an interval with notably lower peak indoor temperatures. Although the solar gains helped to raise the indoor temperature to a more comfortable level than outdoors (daily minimum indoor temperature always exceeded the outdoor temperature by between $1.5^{\circ} \mathrm{C}$ and $11^{\circ} \mathrm{C}$ ), it could not prevent the interior from becoming uncomfortably cold at times. The internal temperature varied significantly between days or even within a single day, demonstrating that the management had very limited control. The 2-hourly data (Figure 10) reveals that the interior could change from being uncomfortably cold to unbearably hot within a few hours. On 2 June, for instance, the indoor temperature ranged between $8{ }^{\circ} \mathrm{C}$ and $25^{\circ} \mathrm{C}$, and on 1 August the average temperature rose from $20^{\circ} \mathrm{C}$ at $10: 00$ hours to $25^{\circ} \mathrm{C}$ at $14: 00$ hours.

After the exhibition, Paxton and Henry Owen, a royal engineer, who superintended the building operation, made further enquiries into the actual cause of the ventilation problems. Owen used empirical observations and the collected data to produce a final report on the environment, which was published in the First Report. He argued that the ventilation system was not defective, but that the exhibits and the ground floor partitions prevented the ventilators inside the 'machinery in motion department' and the refreshment courts communicating with the ventilators in the rest of the building (Figures 6 and 7). Paxton himself, however, found that the high-level ventilators were too small to expel the hot air accumulating at the top and claimed that this problem could be overcome by enlarging the existing high-level vents or by introducing lantern ventilators above the nave. Although Paxton was not able to implement these improvements at Hyde Park, he introduced a new natural ventilation system after the building was removed from Hyde Park and re-erected

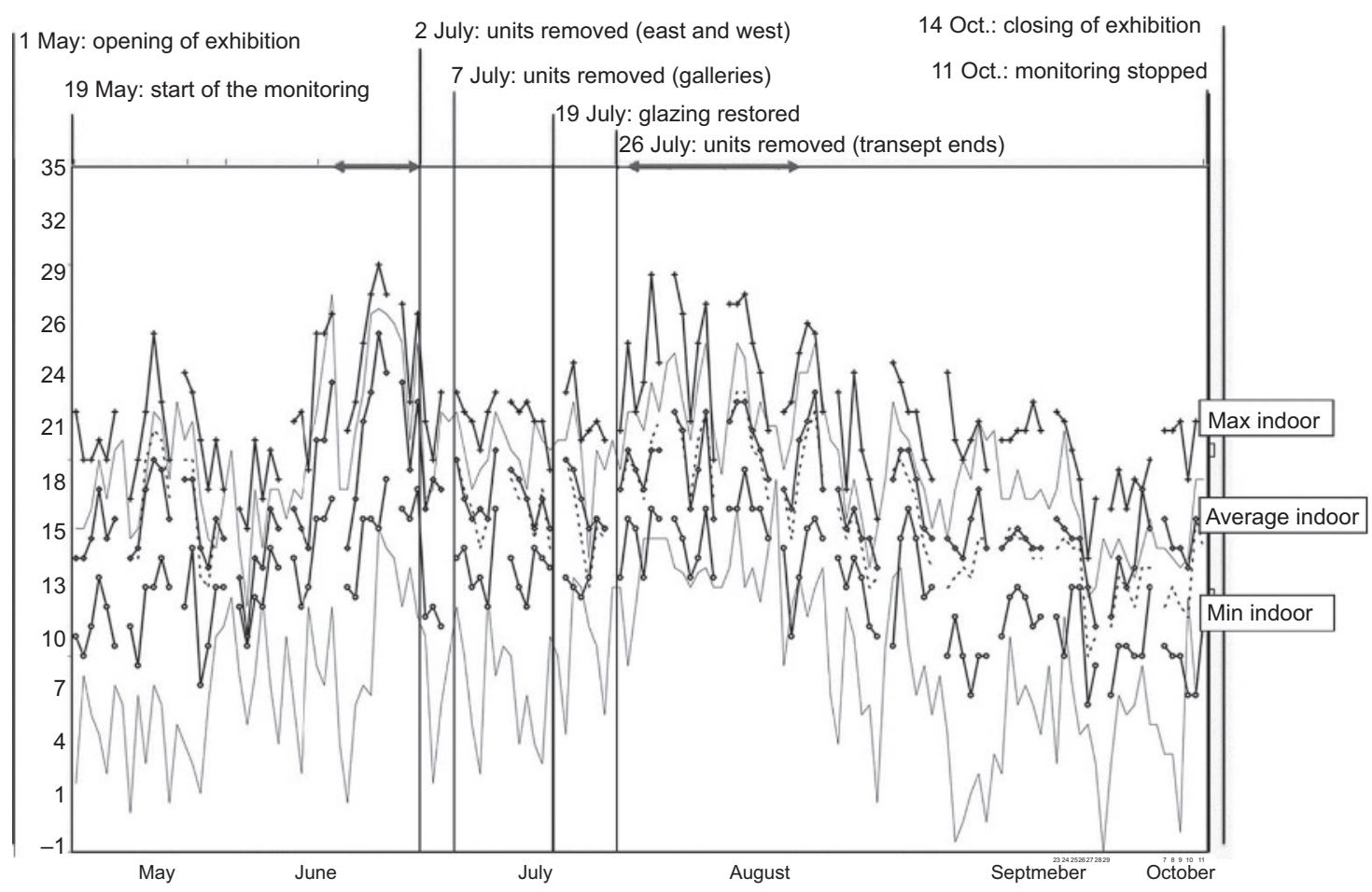

Figure 9. Daily minimum, maximum and mean indoor and outdoor temperatures recorded between 29 May and 11 October 1851 (graph compiled by author, using data published in the First Report of the Commissioners for the Great Exhibition, Commissioners for the Great Exhibition, 1852: pp. $66 \mathrm{f}$ and in the Gardener's Chronicle) 
Creating the right internal

climate for the Crystal Palace

Schoenefeldt

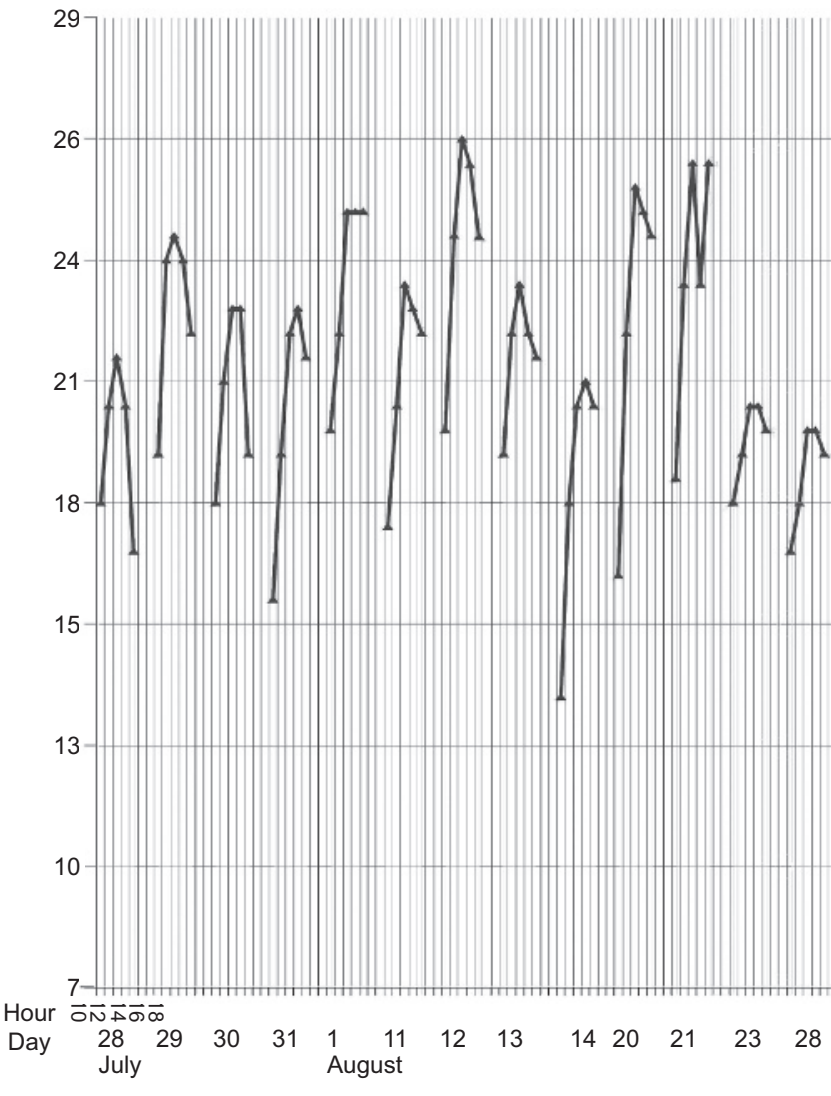

Figure 10. Two-hourly temperatures recorded inside the exhibition building between 28 July and 28 August 1851 (graph compiled by author, using data published in nineteenth-century newspapers)

on its new site at Sydenham. A detailed study of the remodelling of the ventilation system has been published in Architectural History, which shows that Paxton's enquiries to adapt glasshouses for human purposes were continued at Sydenham.

\section{Conclusion}

This paper has shown that the great exhibition building represented a conscious effort to adapt the horticultural glasshouse specifically for humans and artefacts. In this process particular care was taken in achieving the right internal climate for the exhibition, and Paxton's specialist skills as a glasshouse designer were critical to achieve these objectives. A post-occupancy study was conducted to evaluate the efficiency of the environmental strategy, which included the testing of various modifications to the ventilation during the exhibition. The building was used as an environmental design experiment, which provided first-hand insights into difficulties with managing the climate inside glass structures through natural ventilation and shading alone, with no mechanical heating or cooling. The post-occupancy study suggests that Paxton's experience was insufficient to be entirely successful for the Hyde Park building, but the study provided Paxton with new insights, which directly informed his plans for remodelling the original structure at Sydenham. This shows that an iterative design process was used to adapt the glasshouse environment for non-horticultural purposes, with the great exhibition building and its Sydenham reincarnation acting as two consecutive environmental design experiments.

\section{REFERENCES}

Addis B (2006) The Crystal Palace and its place in structural history. International Journal of Space Structures 21(1): 3 19.

Commissioners for the Great Exhibition (1852) First Report of the Commissioners for the Great Exhibition of 1851. HMSO, London, UK, p. 7; pp. 67-68.

Downes C and Cowper C (1852) The Building Erected in Hyde Park for the Great Exhibition. John Weale, London, UK.

Hitchcock HR (1958) Early Victorian Architecture in Britain. Penguin, Harmondsworth, UK.

Hix J (1996) The Glasshouse. Phaidon, London, UK.

Kohlmaier G and von Sartory B (1986) Houses of Glass: a Nineteenth-century Building Type. MIT Press, Cambridge, MA, USA.

Koppelkamm S (1981) Glasshouses and Wintergardens of the Nineteenth Century. Rizzoli, New York, USA.

McKean J (1994) Crystal Palace - Joseph Paxton and Charles Fox. Phaidon, London, UK.

Mallet R (1862) The Record of the International Exhibition 1862. William Mackenzie, Glasgow, Edinburgh, London, UK.

Markham V (1935) Paxton and the Bachelor Duke. Hodder and Stoughton, London, UK.

Paxton J (1836) Observations on the construction of hot-house roofs. Paxton's Magazine of Botany 2: 80-85.

Peters T (2000) Some structural problems encountered in the building of the Crystal Palace of 1851 In Studies in the History of Civil Engineering (Thorne R (ed.)). Ashgate, Aldershot, UK, pp. 1-15

Physick J (1982) The Victoria and Albert Museum: the History of its Building. Phaidon, Oxford, UK.

Schoenefeldt H (2008) The Crystal Palace - environmentally considered. Architectural Research Quarterly 12(1/3): 283294.

Schoenefeldt H (2011a) The Transformation of the Horticultural Glasshouse Prototype for Human Habitation, $\mathrm{PhD}$ thesis, University of Cambridge, Cambridge, UK.

Schoenefeldt H (2011b) Adopting glasshouses for human use: environmental experimentation in Paxton's designs for the 1851 Great Exhibition Building and the Crystal Palace, Sydenham. Architectural History 54: 233-273 
Seymour, Cubitt W and Lindley J (1854) Report of the Commissioners appointed to inquire into the cost and applicability of the exhibition building in Hyde Park. HMSO, London, UK, questions 283-477.
Thorne R (1987) Paxton and prefabrication. Architectural Design 57(11/12): 23-28.

Yanni C (1999) Nature's Museums: Victorian Science and the Architecture of Display. Athlone, London, UK.

\section{WHAT DO YOU THINK?}

To discuss this paper, please email up to 500 words to the editor at journals@ice.org.uk. Your contribution will be forwarded to the author(s) for a reply and, if considered appropriate by the editorial panel, will be published as discussion in a future issue of the journal.

Proceedings journals rely entirely on contributions sent in by civil engineering professionals, academics and students. Papers should be $2000-5000$ words long (briefing papers should be 1000-2000 words long), with adequate illustrations and references. You can submit your paper online via www.icevirtuallibrary.com/content/journals, where you will also find detailed author guidelines. 